Volume 33 (1), pp. 35-55

http://orion.journals.ac.za
ORiON

\title{
2014 Election forecast - a post-election analysis
}

\author{
HW Ittmann* JP Holloway ${ }^{\dagger} \quad$ N Dudeni-Tlhone ${ }^{\dagger}$ \\ Received: 3 September 2016; Revised: 2 March 2017; Accepted: 8 May 2017
}

\begin{abstract}
General elections are held every five years in South Africa. During the 12 to 24 hour period after the close of the voting booths, the expected final results are of huge interest to the electorate and politicians. In the past, the Council for Scientific and Industrial Research (CSIR) has developed an election forecasting model in order to provide the media and political analysts with forecasts of the final results during this period of peak interest. In formulating this model, which forecasts the election results as the results from voting districts (VDs) become available, some assumptions had to be made. In particular, assumptions were made about the clustering of previous voting patterns as well as the order in which VD results are released.

This election forecasting model had been used successfully for a number of elections in the past and in these previous elections, with around $5 \%-10 \%$ of the results available, the predictions produced by the model were very close to the final outcome, particularly for the ANC, being the largest party. For the 2014 national election, however, the predictions, with close to $50 \%$ of the voting district results known (equivalent to an estimated $40 \%$ of the total votes), were still not accurate and varied by more than $1 \%$ for both the ANC and the EFF. This paper outlines a post-election analysis to determine the reasons for these discrepancies and how they relate directly to the model assumptions. The aim is to highlight how practical realities can affect the assumptions and consequently their impact on the forecasted results. Reference is made to previous election forecasts and the 2014 post-election analysis is presented.
\end{abstract}

Key words: Forecasting, elections, assumptions, post-election analysis.

\section{Introduction}

In most democratic countries, general elections are held every four or five years. The outcome of elections causes great interest amongst both the electorate and politicians. The electorate are keen to know who will govern them for the next number of years while

${ }^{*}$ Corresponding author: (Fellow of the Operations Research Society of South Africa), Institute for Logistics and Transport Systems (ILTS) Africa, University of Johannesburg, Johannesburg, South Africa, email: hittmann01@gmail.com

${ }^{\dagger}$ Decision Support and Systems Analysis Research Group, Built Environment, CSIR, Pretoria, South Africa

http://dx.doi.org/10.5784/33-1-567 
the politicians need to prepare themselves for whatever the outcome might be. Forecasting election outcomes has become a serious business [14]. Long before an election the media and political scientists speculate, conduct surveys, etc. to determine what the support for the various political parties are and from this endeavour to forecast what the possible outcome of the election could be. Knight [24] quotes Karl Popper who already recognised the value of predictions or forecasts because "it connects subjective and objective reality".

After the elections the media, the electorate and the country are all keen to get a sense of what the final outcome of the election will be. For the 12 to 24 hours after the close of the voting booths, the expected final results are of huge interest. For this reason, in South Africa, the South African Broadcasting Corporation (SABC) contracted the Council for Scientific and Industrial Research (CSIR) from 2004 onwards to forecast the final results as soon as the first results from voting districts (VDs) are made available. A statistically based forecasting model had already been developed by the CSIR for the 1999 and 2000 elections and this same model was then utilised to provide news-worthy predictions for the SABC for subsequent elections. For most of the elections the model performed reasonably well. With around $10 \%$ of the results available the model forecasts were fairly accurate in predicting the final national results, especially for the larger political parties and in particular for the African National Congress (ANC), being the largest party. However, during the most recent national election in 2014, with almost 50\% of VDs declared (equivalent to about $40 \%$ of the votes counted), the national forecast still deviated fairly significantly from the final result for two of the political parties. With $50 \%$ of VDs declared, the forecast should have started to converge to the final outcome with the difference between the forecasted and the final result being very small or almost the same. However, in 2014, with $49.3 \%$ of VDs declared, the predicted national result forecasted for the ANC and the new Economic Freedom Fighters (EFF) party differed by $1.15 \%$ and $1.56 \%$ respectively from the actual final outcome. These predictions were considered to be unacceptable and contrary to experiences from previous elections. This article analyses, post-election, the reasons for this discrepancy and endeavours to explain why this difference was prevalent with half of the VDs declared. The discrepancies are related to the assumptions made in formulating and using the model. Assumptions are usually part of the modelling exercise and modellers typically know that they need to interpret the results taking the assumptions into consideration. This paper identifies how practical realities can affect the impact of the assumptions and therefore the forecasted results.

The rest of the paper is structured as follows. The first two sections contain a literature review of previous election forecasts followed by a very brief outline of the forecasting model and a discussion on model assumptions. Following that, the forecasting results of the two national elections and two municipal elections, prior to 2014, are presented and then compared to the 2014 results. The 2014 election forecast results are discussed and analysed in detail. A short discussion on model assumptions is given and finally some conclusions follow.

\section{Literature review}

Forecasting the outcome of an election aims to declare the end result before it happens [26]. Lewis-Beck defines two types of forecasting namely scientific and non-scientific. The latter 
is based on speculation, non-systematic interviews, etc. while scientific forecasts include simulations, market analysis, sample surveys or statistical models. These four scientific methods are typically used to forecast the outcome of an election before the event. However, there are also methods used to predict the outcome after the election has occurred. In the United Kingdom, for example, it is now almost tradition that there are exit polls where voters are asked which party or candidate they voted for straight after they have voted. With appropriate samples sizes a forecast of the outcome is presented almost as soon as the election booths close. In South Africa a forecasting model was developed which endeavours to forecast the final outcome based on the first results as they become available $[12,13]$. The model is thus used after the event to forecast the final outcome.

With any forecast there is no certainty that it will be correct; Silver [34] states that "we can never make perfectly objective predictions". Part of the reason is that no one can predict the uncertain future, but there is a further contributing factor, namely the assumptions made in formulating the model. One would expect that scientifically based forecasting models and their assumptions should be properly tested and validated beforehand ensuring results are reliable and fairly close to the ultimate outcome. Is this always true? Recent examples of election forecasts are given to illustrate the phenomena of incorrect forecasts, some "before the event" forecasts as well as "exit polls" forecasts. The three examples are provided to indicate that elections forecasts can be wrong - there is no effort or endeavour to explain the underlying reasons for the inaccuracies.

During the 2015 national election in the UK the polls, for months before the election consistently forecasted and indicated the following percentages, give or take small variations, of support for the various parties: Conservative 34\%; Labour 33\%; UKIP 13\%; Liberal Democrats 8\%; Green 5\%; and Others 7\% [4]. Based on these predicted numbers there was a general belief that the outcome of the election would result in a hung parliament which would require a coalition government. Compared to the final percentages for each of the parties, these forecasts were incorrect by a large margin. The final election result in the UK was (percentage votes are given in brackets): Conservative 36.9\%; Labour 30.4\%; UKIP 12.6\%; Liberal Democrats 7.9\%; Green 3.8\%; and Others 7.5\% [3]. The ultimate results for the larger parties were totally different from the before election forecasts.

In Israel elections were held on 17 March 2015. There it is illegal to publish any polls in the last five days before an election. The final pre-election polls published on 13 March 2015 suggested that the Likud party would get 22 seats while the Zionist Union 25 . The exit polls predicted that each party would win 27 seats each. The actual result was 30 for Likud and 24 for the Zionist Union [11]. Again there were substantial differences.

In South Africa the market research company Ipsos undertakes a "Pulse of the People" study [20], or survey, every six months and reports on possible voter behaviour. A randomly selected sample of South Africans of voting age (18 plus) are asked which party they would support if there was an election the next day. Voter turnout is an influencing factor and Ipsos develops an index of possible voter turnout. The survey thus reports on three turnout scenarios namely low, moderate and high voter turnout. The results of the November 2013 [20] and April 2014 [21] surveys for these three scenarios are reflected in Table 1. In both surveys Ipsos indicate clearly that sample surveys are subject to a margin of error, determined by sample size, response rate and sampling methodology used. The 
margin of error for the "Pulse of the People" survey is 1.67 for the sample as a whole.

\begin{tabular}{|c|c|c|c|c|c|c|c|}
\hline \multirow{3}{*}{$\begin{array}{l}\text { Political } \\
\text { party }\end{array}$} & \multicolumn{6}{|c|}{ Turnout scenarios } & \multirow{3}{*}{$\begin{array}{c}\begin{array}{c}\text { Final } \\
\text { result }\end{array} \\
05 / 2014\end{array}$} \\
\hline & \multicolumn{2}{|c|}{$\begin{array}{l}\text { Low Voter } \\
\text { Turnout \% }\end{array}$} & \multicolumn{2}{|c|}{$\begin{array}{l}\text { Moderate Voter } \\
\text { Turnout \% }\end{array}$} & \multicolumn{2}{|c|}{$\begin{array}{l}\text { High Voter } \\
\text { Turnout \% }\end{array}$} & \\
\hline & $11 / 2013$ & $04 / 2014$ & $11 / 2013$ & $04 / 2014$ & $11 / 2013$ & $04 / 2014$ & \\
\hline $\mathrm{ANC}$ & 65 & 65.5 & 64 & 63.4 & 56 & 60.2 & 62.15 \\
\hline DA & 19 & 20.7 & 19 & 22.9 & 18 & 23.3 & 22.23 \\
\hline $\mathrm{EFF}$ & 4 & 4.2 & 4 & 4.7 & 4 & 5.3 & 6.35 \\
\hline ACDP & 1 & 1.1 & 1 & 0.9 & 1 & 0.9 & 0.57 \\
\hline AGANG & 1 & - & 1 & - & 1 & - & 0.26 \\
\hline COPE & 1 & 1.7 & 1 & 1.2 & 1 & 1 & 0.67 \\
\hline IFP & 2 & 1.9 & 2 & 1.9 & 1 & 2.3 & 2.4 \\
\hline Other parties & 1 & 4.9 & 2 & 5 & 3 & 7 & 5.37 \\
\hline Will not vote & - & - & - & - & 7 & - & \\
\hline No answer & 4 & - & 4 & - & 5 & - & \\
\hline Don't know & 2 & - & 2 & - & 3 & - & \\
\hline
\end{tabular}

Table 1: Ipsos market research surveys of \% voter support for the different political parties in November 2013 and April 2014.

Comparing the Ipsos forecast before the election to the final outcome, using the moderate voter turnout scenario from April 2014, the ANC and EFF results differed by $1.25 \%$ and $1.65 \%$, respectively. These differences are considerably larger with the low and high voter turnout scenarios.

Rothschild [31] explored the accuracy and content of forecasts derived from polls data and prediction markets in the USA. He concludes that both these suffer from inherent biases and demonstrate that "in not-certain elections de-biased prediction market-based forecasts provide more accurate probabilities of victory and more information than debiased poll-based forecasts".

In the USA 2012 election, Silver [34] was very successful in correctly predicting the outcome in all 50 states. Taking many factors into account Silver has developed statistically based prediction models not just for elections but in many other areas such as sport and financial markets. His one main and overriding principle is that his forecasts are probabilistic implying that the models produce a range of possible outcomes. As elections dates approach the range of possible outcomes decreases. In the case of the 2012 Presidential election, Silver forecast that President Obama would win with a probability of $90 \%$.

Over and above what has been presented in this section, many different types of election forecasting models and methodologies exist that are being used internationally [7, 23, 25, 27, 28, 32, 36]. Models are continuously being improved and they are becoming more and more sophisticated [34]. Elections, voting procedures, fair representation and seat allocation methods are a fertile ground for mathematicians [2, 10, 35].

When South Africa became a democracy in 1994 it changed its electoral system to that of proportional representation [1]. In such a system the electorate vote for a political party and the number of votes determine the seats allocated to that party. The methodology used for this is also not covered in this paper.

This paper focusses on what went wrong with the election forecast during the 2014 na- 
tional election in South Africa. The results as they became available are scrutinised, investigated and compared to the final voter counts to determine this aspect. From a modelling perspective, the impact of assumptions on the behaviour and results produced by the forecasting model is highlighted. From the literature found, there does not seem to be many articles published on this topic.

\section{Model and assumptions}

The aim of this paper is not to describe the model since a detailed outline of this model is given by Greben et al. [12] as well as by Greben et al. [13]. Further, Ittmann [22] gives some personal perspectives and experiences of interacting with the media in sharing the forecasts produced by this model. It is, however, important to highlight that this model operates on two major assumptions. Firstly, it is assumed that voting behaviour has a statistical pattern that can be modelled by clustering the VDs into segments with similar voting behaviour. Secondly, the order in which the voting results are released (or declared) is important. The model is designed to adjust for moderate non-random patterns in this order but will not operate well under extreme political or spatial bias.

\subsection{Assumption 1}

This prediction model is informed by understanding voter behaviour which specifically involves grouping the voting population into clusters. That is, VDs with similar voting patterns are grouped together to form clusters or segments which represent voting behaviour of the entire electorate. Therefore, the first assumption of the prediction model is that VDs belonging to one cluster share similar voting patterns and are likely to maintain similar voting behaviour as in the past, or if there are changes to the future voting patterns, then such voting shifts will occur similarly across all VDs in that cluster. It is important to note that every voter belongs to a VD which in turn gets grouped into one of the clusters to represent voting tendency. Hence, grouping the voting population highlights predominant and distinct voting patterns that are needed to inform the prediction model. This clustering enables the model to roll out the available voting results (from only a few VDs) to the appropriate clusters so as to achieve good predictions of an election outcome in those relevant groups of the voting population. One other important characteristic of the clusters is that each VD is allowed to belong to more than one cluster or to have memberships across relevant clusters. This flexibility is provided by the clustering approach used, which is known as the fuzzy $c$-means approach $[5,6]$. The strength of this technique lies on quantifying the degree to which a VD belongs to each of the clusters, as opposed to assigning each VD to one and only one cluster.

The construction of clusters involves selecting appropriate distance measures to compute similarity between the VDs. Specifically; this model uses the common Euclidean distance measure, instead of the standardised measure, in order to give emphasis to voting patterns of the larger political parties rather than the smaller ones. Therefore, the model estimates for larger parties are expected to perform better, since they are better represented by the clusters than the smaller parties. Also, in the media reporting context, the performance 
of larger political parties receives more attention, except in a few cases where the newly formed parties, such as the Congress of the People (COPE) (in 2009) and EFF (in 2014), although small in comparison to the ANC, did attract a great deal of political interest.

\subsection{Assumption 2}

The VDs that are first released, from which this model starts to make its initial predictions, is affected by a large number of factors. These factors introduce a bias, or a non-random pattern, into the order in which the South African VD results are received. In an ideal world an analyst usually has control over the process of "data collection" [30] but in this context it is not the case since the analyst has no way of knowing in which order the VD results will be released. The predominant factor that determined the order in the past was, for instance, that the election results from urban areas tended to be released much earlier than those from rural parts of the country [13]. More recently, smaller VDs, i.e. with smaller numbers of registered voters, tend to get declared sooner than the larger VDs. Under normal circumstances, the prediction model compensates for a certain level of bias in the order in which the results are obtained, provided each cluster receives data from a sufficient number of representative VDs, since the voting results declared in a few representative VDs can be rolled out to the entire cluster, thereby obtaining good estimates of the expected vote in that relevant segment of the population [13]. Therefore, the second assumption behind the model is that a certain percentage "sample" of VDs whose results are released initially provide a fair representation of voter behaviour which is well distributed across the clusters and can thus be used to represent those VDs across the country for which the results are still outstanding. Furthermore, the model also assumes that as the "sample size" of VD results received increases, these results become more representative of the clusters, and hence of the entire country. Consequently the model predictions become more reliable and less erratic as more VD results become available.

In model formulation it is almost always unavoidable to make assumptions, but it is then important to understand how these assumptions affect the results and the interpretation thereof. Such understanding can also provide insights for model improvements. In the next section, forecasts obtained from using this model are presented based on previous elections in South Africa. A short discussion of the results is given and interesting aspects are also highlighted. It is then shown that during the 2014 election, the accuracy of the forecasts was influenced by these assumptions. The results are discussed and illustrated in detail, and where applicable, reference is made to the assumptions influencing the predictions.

\section{Previous election forecasts versus final results}

In order to provide the context for a discussion on prediction accuracy, the prediction results are first presented from the 4 elections prior to 2014 .

\subsection{Elections 2004-2011}

For 2004 and 2009, which were national elections, the predictions are presented for the national vote while for the local municipal elections in 2006 and 2011 the predictions 
are presented for the PR (Proportional Representation) vote aggregated to a national level. The results given are for the 3 or 4 largest parties, since these are the predictions which attract the most interest. The forecasts for the smaller parties are initially not very accurate and are also not given much focus during the election predictions.

\begin{tabular}{|c|c|c|c|c|c|c|c|c|}
\hline \multirow[b]{2}{*}{ Party } & \multicolumn{4}{|c|}{2004} & \multicolumn{4}{|c|}{2009} \\
\hline & $\begin{array}{c}\text { Actual } \\
\text { at } 4.7 \% \\
\text { votes } \\
\text { counted }\end{array}$ & $\begin{array}{c}\text { Predicted } \\
\text { at } 4.7 \% \\
\text { votes } \\
\text { counted }\end{array}$ & $\begin{array}{c}\text { Deviance of } \\
\text { predicted } \\
\text { from } \\
\text { final at } \\
4.7 \% \text { votes }\end{array}$ & $\begin{array}{l}\text { Final } \\
\text { result }\end{array}$ & $\begin{array}{c}\text { Actual } \\
\text { at } 5.0 \% \\
\text { votes } \\
\text { counted }\end{array}$ & $\begin{array}{c}\text { Predicted } \\
\text { at } 5.0 \% \\
\text { votes } \\
\text { counted }\end{array}$ & $\begin{array}{l}\text { Deviance of } \\
\text { predicted } \\
\text { from } \\
\text { final at } \\
5.0 \% \text { votes }\end{array}$ & $\begin{array}{c}\text { Final } \\
\text { result }\end{array}$ \\
\hline $\mathrm{ANC}$ & 60.88 & 69.76 & 0.08 & 69.68 & 61.19 & 65.59 & 0.32 & 65.91 \\
\hline DA & 21.99 & 14.08 & 1.71 & 12.37 & 21.18 & 17.32 & 0.68 & 16.64 \\
\hline IFP & 3.26 & 5.69 & 1.28 & 6.97 & 2.77 & 4.15 & 0.40 & 4.55 \\
\hline COPE & & & & & 7.25 & 6.83 & 0.59 & 7.42 \\
\hline
\end{tabular}

Table 2: Comparison of forecasts and actuals for 2004 and 2009 national elections.

\begin{tabular}{|c|c|c|c|c|c|c|c|c|}
\hline \multirow[b]{2}{*}{ Party } & \multicolumn{4}{|c|}{2006} & \multicolumn{4}{|c|}{2011} \\
\hline & $\begin{array}{c}\text { Actual } \\
\text { at } 6.8 \% \\
\text { votes } \\
\text { counted }\end{array}$ & $\begin{array}{c}\text { Predicted } \\
\text { at } 6.8 \% \\
\text { votes } \\
\text { counted }\end{array}$ & $\begin{array}{l}\text { Deviance of } \\
\text { predicted } \\
\text { from } \\
\text { final at } \\
6.8 \% \text { votes }\end{array}$ & $\begin{array}{l}\text { Final } \\
\text { result }\end{array}$ & $\begin{array}{c}\text { Actual } \\
\text { at } 4.9 \% \\
\text { votes } \\
\text { counted }\end{array}$ & $\begin{array}{c}\text { Predicted } \\
\text { at } 4.9 \% \\
\text { votes } \\
\text { counted }\end{array}$ & $\begin{array}{l}\text { Deviance of } \\
\text { predicted } \\
\text { from } \\
\text { final at } \\
4.9 \% \text { votes }\end{array}$ & $\begin{array}{l}\text { Final } \\
\text { result }\end{array}$ \\
\hline ANC & 61.18 & 66.89 & 1.22 & 65.67 & 56.89 & 62.19 & 0.74 & 62.93 \\
\hline DA & 24.32 & 17.35 & 1.03 & 16.32 & 32.28 & 25.94 & 1.86 & 24.08 \\
\hline IFP & 2.82 & 6.28 & 1.28 & 7.56 & 1.58 & 3.02 & 0.54 & 3.56 \\
\hline COPE & & & & & 3.28 & 2.95 & 0.73 & 2.22 \\
\hline
\end{tabular}

Table 3: Comparison of forecasts and actuals for the 2006 and 2011 municipal elections.

An example is first given of the early predictions, compared to actual count at the same time and to the final results [15, 17], in Table 2 for the 2 national elections prior to 2014, and in Table 3 for the 2 municipal elections $[16,18]$ that took place before 2014. Note that results are given here in terms of percentage votes counted and at any point in time, this value is generally lower than the percentage VDs declared since the smaller VDs tended to come in earlier. The percentage votes counted is an estimated value from the model using the number of votes received and the expected number still outstanding, with the latter calculated using a predicted turnout for each cluster and the registered population of voting districts.

Due to the way in which the model works, predictions become more stable and accurate as more voting districts are counted, with the predictions converging to the final result once all voting districts are declared. However, to illustrate the accuracy of the model at an early stage of the count the predictions are presented after roughly $5 \%$ of votes have been counted. Unfortunately, since predictions were not always generated at regular percentage vote intervals, the only available comparable reading in 2006 was at $6.8 \%$ of votes counted. A brief discussion highlighting a few political points of interest is also given. These first results are just illustrative but a more comparative analysis will be given later in this section.

Before the 2004 national election, the old National Party (NP) was renamed to the New National Party (NNP) but it was clear that many of the old NP supporters would probably support the Democratic Alliance (DA) and that the DA would become the formal 
opposition. This election was the end of the road for the old National Party as well as the NNP, the party that replaced it. The early predictions on the morning of Thursday 15 April 2004 with only $5 \%$ of the votes counted (see Table 2) were, at least for the ANC, almost spot-on! This forecast for the ANC can be ascribed to the fact that the ANC was by far the largest party and therefore well represented by the clusters. The small number of votes counted already represented the ANC support across the clusters fairly well, even though the actual percentage counted for the ANC deviated roughly $9 \%$ from the final result at the time. For the ANC both assumptions were satisfied, while the DA and Inkatha Freedom Party (IFP) forecasts, being much smaller parties than the ANC, were still about $1.7 \%$ and $1.3 \%$ off the final result respectively and took longer to converge to the final result (with the DA forecast only getting within $1 \%$ of the final result once almost $40 \%$ of the votes had been counted). However, compared to what the actual percentage was for the DA at the time (after $5 \%$ of the votes counted), the predictions still gave the media a good indication of where the party might end up by the end of the vote count.

The 2006 elections were held 12 years into the democracy around the time when a few demonstrations had occurred and dissatisfaction with the rate of service delivery was becoming evident. This election was seen as a challenge to the ANC which received a majority of seats with about $65.7 \%$ of the national aggregated PR vote. The DA on the other hand took approximately $16.3 \%$ of the PR vote at the national level and won the largest share of votes in the City of Cape Town. The IFP remained the third largest national party with $7.6 \%$ of the vote and won the majority in Kwa-Zulu Natal province. With respect to the PR vote predictions aggregated to a national level, all three top parties were slightly more than $1 \%$ away from the final result after $6.8 \%$ of the votes had been counted (see Table 3).

What was interesting during the 2009 election was that a significant number of voters split from the ANC and established the Congress of the People (COPE) party. COPE was thus in opposition to the ANC and also a totally new party in this election. On Thursday 23 April 2009, with roughly $5 \%$ of the votes counted, the early forecasts for all four of the largest parties were very close to the final outcome. The forecasts in all cases differed from the final result by less than a percentage point with the largest difference being that for the DA, namely $0.7 \%$.

Two things stand out from the 2009 election. Firstly the prediction of the final percentage of votes for COPE, with $5 \%$ of the results available, was very close to the final result, as was the actual count at that time. This implied that the swing from the ANC to COPE was captured well by the clusters but also that the COPE vote counted at that stage was representative of the national support for COPE. It illustrated that the model was robust enough to accommodate and handle a new political party. In addition, the two modelling assumptions proved to be realistic for this new party. Secondly there was huge interest from the electorate and the media as to whether the ANC would receive a more than two third majority. The model predicted that this was not going to happen even though the ANC, after about $90 \%$ of the votes had been counted, had over $67 \%$ of the declared votes. As a result of this enormous political interest the predictions remained in the media spotlight for a more extended period than any other election. The fact that the predictions were correct was further proof of the validity of the model assumptions. 
During the 2011 municipal election it was clear that South Africa was moving more and more towards a two party system, particularly when it came to the way that people voted at a local level. With roughly $5 \%$ of the votes counted, the forecast for the ANC was only about $0.7 \%$ off the final result while the forecast for the DA still had a deviance of about $1.9 \%$ from their final tally (and only came within $1 \%$ of the final results after about $10 \%$ of votes had been counted). Clearly $5 \%$ of votes counted was still too little in the case of the DA to calculate a more accurate forecast, illustrating the impact of the model assumptions, i.e. assumption 2 which assumes that the initial sample of VD results released would provide a fair representation of voter behaviour well distributed across the clusters did not hold true for the DA, mainly due to a large degree of bias in the initial $5 \%$ of VDs counted, which contained high DA votes and which had memberships concentrated in a few clusters, thus causing an over-estimation of the DA percentage prediction in those clusters.

\subsection{Latest national elections -2014}

Leading up to the 2014 elections, a new party emerged, namely the EFF, which was expected to take some support away from the ANC and attract a portion of the ANC votes. On the strength of the previous election prediction results and the good prediction results for the new COPE party in the 2009 elections, it still seemed appropriate that the predictions for the 3 or 4 main parties, and in particular for the ANC, should provide a fairly accurate result at about $5 \%$ and should have at least started stabilising after about $10 \%$ of the votes have been counted. Table 4 shows the predictions when roughly $5 \%$ and $40 \%$ of the votes were counted for the top 4 parties, compared to the actual count at the same time and compared to the final results. Note that COPE had lost nearly all of the support that they had achieved in the 2009 elections and ended with $0.67 \%$ and therefore are not included in the comparison.

\begin{tabular}{|c|c|c|c|c|c|c|c|}
\hline \multirow[b]{2}{*}{ Party } & \multicolumn{3}{|c|}{$2014(4.7 \%)$} & \multicolumn{3}{|c|}{$2014(40.2 \%)$} & \multirow[b]{2}{*}{$\begin{array}{l}\text { Final } \\
\text { result }\end{array}$} \\
\hline & $\begin{array}{c}\text { Actual } \\
\text { at } 4.7 \% \\
\text { votes } \\
\text { counted }\end{array}$ & $\begin{array}{c}\text { Predicted } \\
\text { at } 4.7 \% \\
\text { votes } \\
\text { counted }\end{array}$ & $\begin{array}{c}\text { Absolute } \\
\text { deviance } \\
\text { between } \\
\text { predicted } \\
\text { and final } \\
\text { at } 4.7 \% \\
\text { votes }\end{array}$ & $\begin{array}{c}\text { Actual } \\
\text { at } 40.2 \% \\
\text { votes } \\
\text { counted }\end{array}$ & $\begin{array}{c}\text { Predicted } \\
\text { at } 40.2 \% \\
\text { votes } \\
\text { counted }\end{array}$ & $\begin{array}{c}\text { Absolute } \\
\text { deviance } \\
\text { between } \\
\text { predicted } \\
\text { and final } \\
\text { at } 40.2 \% \\
\text { votes }\end{array}$ & \\
\hline $\mathrm{ANC}$ & 53.85 & 63.83 & 1.68 & 61.74 & 63.30 & 1.15 & 62.15 \\
\hline DA & 33.63 & 22.18 & 0.05 & 23.58 & 21.89 & 0.34 & 22.23 \\
\hline IFP & 1.66 & 2.14 & 0.26 & 2.37 & 2.37 & 0.03 & 2.40 \\
\hline $\mathrm{EFF}$ & 3.31 & 3.96 & 2.39 & 4.62 & 4.79 & 1.56 & 6.35 \\
\hline
\end{tabular}

Table 4: Comparison of actual, predicted and final results for the 2014 national elections at roughly $5 \%$ and $40 \%$ of votes counted.

With only $5 \%$ of the votes counted in the 2014 elections, the prediction for the DA and IFP were very close to the final outcome but this was not the case for the ANC and the EFF. Even with this small percentage of votes counted one would have expected that the ANC prediction would have been better and even for the EFF, although being a new and small party and therefore less accuracy expected, the prediction was still more than $2 \%$ out. 
When $40.2 \%$ of the votes were counted (equivalent to the previously mentioned $49.3 \%$ of VDs declared) one would have expected that the predictions, especially for the ANC as the largest party, should have converged to values very close to the final result and to be at least within $1 \%$ of the final result. As can be seen in Table 4, however, the prediction at roughly $40 \%$ of votes counted for the ANC was still $1.15 \%$ too high and for the EFF was $1.56 \%$ too low. Having a higher than $1 \%$ difference from the final outcome at a time when almost half of the voting count information, nationally, was available seemed to indicate predictions less accurate than one would expect from this type of model.

It is interesting that the Ipsos "before the election" prediction based on a market survey for the moderate voter turnout scenario showed similar patterns (see Table 1). The prediction for the ANC was overstated while that of the EFF was understated, but it is impossible to know what the reasons may have been in the case of that survey.

\subsection{Comparison of elections 2004-2014}

In order to do a more comparable analysis of the accuracy of election predictions over "time" (percentage votes counted), and to determine the typical value for percentage votes counted at which predictions are within an acceptable range of accuracy, two errors were computed. Firstly a deviance per party at each time unit and secondly an overall mean absolute error (MAE) at each time unit. Note that for the purpose of this paper, "time units" does not refer to actual time elapsed but rather the estimated percentage of votes that have been counted.

The deviance per party at a time unit (percentage votes counted) is simply calculated as the difference between the percentage for that party at time $t$ and the actual percentage obtained by the party at the end of the election. The MAE at each time unit is simply calculated as the average absolute deviance at that time unit for the 3 main parties contesting the election.

\begin{tabular}{cccccc}
\hline & \multicolumn{2}{c}{$\begin{array}{c}\text { Percentage votes counted when error } \\
\text { measure drops and stays below }\end{array}$} \\
\cline { 2 - 3 } Election year & \multicolumn{2}{c}{ MAE } & & \multicolumn{2}{c}{ ANC deviance } \\
\cline { 2 - 3 } \cline { 5 - 6 } & Predicted & Actual & & Predicted & Actual \\
\hline 2004 & 10 & 76 & & 1 & 51 \\
2006 & 9 & 51 & & 9 & 38 \\
2009 & 4 & 41 & & 4 & 90 \\
2011 & 8 & 47 & & 9 & 50 \\
2014 & 42 & 42 & & 45 & 36 \\
\hline
\end{tabular}

Table 5: Table of percentage votes counted at which the MAE (for the top 3 parties) and ANC deviance dropped and stayed below 1\%, for predicted and actual values in 5 elections.

For comparative purposes, a deviance of below $1 \%$ for the ANC prediction and MAE, for the 3 main parties, of below $1 \%$ are considered to be acceptable levels of accuracy. Table 5 gives the values of the percentage votes counted at which the MAE and deviance of the ANC result drops and stays below $1 \%$, for both the predicted and actual values for all 5 elections. 


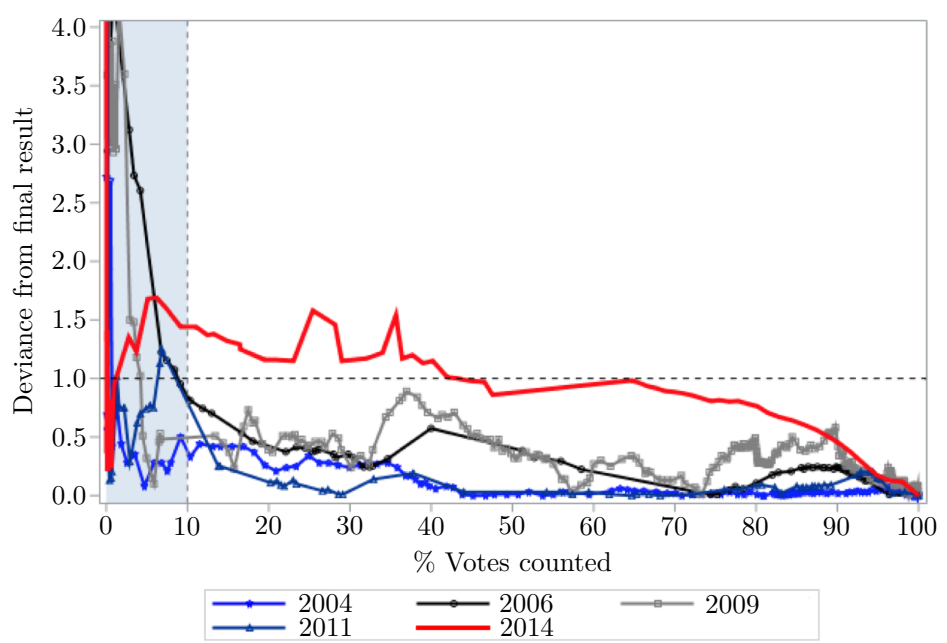

Figure 1: Deviance of ANC prediction from final result over percentage votes counted, for 5 elections.

From Table 5 one can see that during elections 2004-2011, the deviance for the MAE for the top 3 parties was always within $1 \%$ after at most $10 \%$ of the votes had been counted and the deviance for the ANC prediction was always within $1 \%$ of the final result after at most $9 \%$ of the votes had been counted. Therefore, the results from these 4 previous elections indicate that one can start to consider the predictions to be within a reasonable level of accuracy once at least $10 \%$ of the votes have been counted. For the actual percentage count, however, the MAE of the actual values relative to the final outcome has in the past only fallen below $1 \%$ after at least $41 \%$ of the votes have been counted (in 2009) and at most after $76 \%$ of the votes have been counted (in 2004).

For the 2014 elections these figures, shown in Table 5, were quite different. In 2014, the MAE of the predicted values for the top 3 parties only dropped below $1 \%$ once $42 \%$ of the votes had been counted — the same accuracy as the actual count — and for the ANC deviance, the predicted values appear to achieve an acceptable level of accuracy later than the actual count. These results for the predictions are further emphasized in the next 2 figures. Figure 1 displays the deviance for the ANC predictions in the previous elections relative to the 2014 deviance, with the shaded band indicating the typical period (from elections 2004-2011) of model instability after which the ANC predictions can be considered to be within a $1 \%$ deviance of the final election outcome. Figure 2 displays a similar plot but for the MAE of the top 3 parties, rather than just for the ANC. Note that instability in the 2009 election predictions, even in the later part of the vote count, seen in Figures 1 and 2, was mainly due to errors in the forecasting software rather than in the model formulation and model assumptions. Namely, the software program assumed erroneously that the national and provincial results are released at the same time (as occurred in elections prior to 2009) but during the 2009 election, the Independent Electoral Commission (IEC) frequently released provincial votes for a voting district while the national votes were held back and consequently the model used zero counts if national results were absent. This also affected the turnout predictions with zero turnouts being estimated in some districts. However, despite these programming errors, the model still proved itself to be robust enough to provide reasonable forecasts during the 2009 elections. 


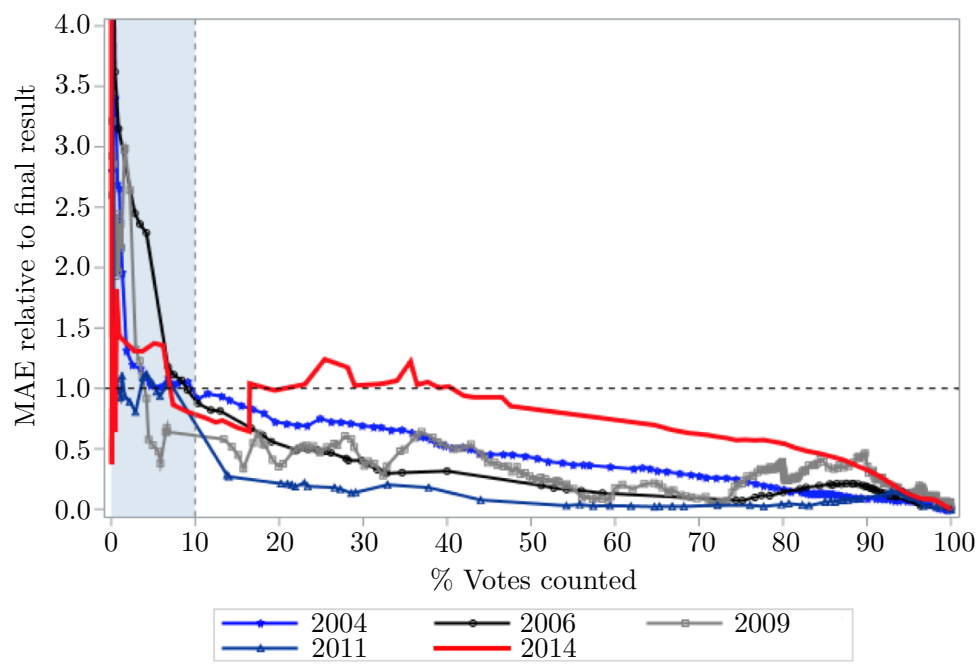

Figure 2: MAE relative to final result for top 3 party predictions, for 5 elections.

\subsection{Post-election analysis of poor performance in 2014}

The poor performance of the ANC and EFF prediction results in 2014 were contrary to all previous elections forecasts and therefore deemed not acceptable. Closer interrogation of the results, available at that stage, was therefore necessary to determine why this was the case and whether it was due to the violation of the model assumptions. The post-election analysis therefore took the form of assessing whether the poor performance of the national forecasts for the ANC and EFF parties was a result of the clusters being inadequate (i.e. a violation of assumption one) or whether it was due to excessive bias in the order in which voting districts were declared (i.e. violation of assumption two), since voting districts with high percentages of EFF votes happened to have been submitted fairly late in the counting process.

\begin{tabular}{lcccc}
\hline Province & $\begin{array}{c}\text { No. of VDs } \\
\text { counted at } \\
\mathbf{1 1 : 2 4}\end{array}$ & $\begin{array}{c}\text { Total } \\
\text { number of } \\
\text { VDs }\end{array}$ & $\begin{array}{c}\text { Percentage of VDs } \\
\text { counted at provincial } \\
\text { level at 11:24 }\end{array}$ & $\begin{array}{c}\text { Voter } \\
\text { turnout } \\
\text { \% }\end{array}$ \\
\hline National & 10965 & 22261 & 49.3 & 73.0 \\
Gauteng & 475 & 2652 & 17.9 & 73.5 \\
Western Cape & 1230 & 1606 & 76.7 & 74.8 \\
KZN & 2048 & 4751 & 43.1 & 74.0 \\
Northern Cape & 618 & 695 & 88.9 & 70.6 \\
Limpopo & 1078 & 3069 & 35.0 & 60.0 \\
Eastern Cape & 2851 & 4620 & 61.7 & 66.7 \\
Free State & 626 & 1634 & 40.8 & 70.0 \\
North West & 780 & 1724 & 45.2 & 65.9 \\
Mpumalanga & 1197 & 1678 & 71.3 & 72.3 \\
\hline
\end{tabular}

Table 6: Actual VDs declared nationally and per province when an estimated $40 \%$ of votes had been counted - 2014 national election.

Firstly, the number of VDs per province and the percentage of VDs declared per province at 11:24 on Thursday, 8 May 2014 are considered — the time when roughly $50 \%$ of the VDs 


\begin{tabular}{lcccc}
\hline Province & $\begin{array}{c}\text { Actual EFF } \\
\text { percentage } \\
\text { votes (11:24) }\end{array}$ & $\begin{array}{c}\text { Predicted EFF } \\
\text { percentage } \\
\text { votes (11:24) }\end{array}$ & $\begin{array}{c}\text { Final EFF } \\
\text { percentage } \\
\text { votes }\end{array}$ & $\begin{array}{c}\text { Deviance } \\
\text { between } \\
\text { predicted } \\
\text { and final }\end{array}$ \\
\hline Gauteng & 8.4 & 8.2 & 10.26 & 2.06 \\
Limpopo & 9.8 & 9.9 & 10.27 & 0.37 \\
North West & 10.7 & 10.8 & 12.53 & 1.73 \\
\hline
\end{tabular}

Table 7: EFF percentage votes - actual (at 11:24), predicted and final, as well as difference between predicted and final percentage votes — for 3 provinces in 2014 elections.

had been declared nationally (equivalent to an estimated $40 \%$ of national votes counted). These values are given in Table 6 [19].

Very noticeable from Table 6 was that in Gauteng only $17.9 \%$ of the VD results had been declared at that time. The EFF had their strongest support in this province. In addition the percentage VDs declared in Limpopo and North West, where the EFF also had strong support, were below 50\%. By focusing on the EFF numbers, comparing the actual results at that stage $(11: 24)$ with the predictions and the final results for the 3 provinces where the EFF got more than $10 \%$ of the votes, one could get a better sense of what caused this discrepancy in the forecast of the final national results for the ANC and the EFF; see Table 7 [19].

The two provinces where the predicted and final results for the EFF varied the most were in Gauteng and North West while the prediction for Limpopo was fairly acceptable. But why was the full support for the EFF in Gauteng and North West not picked up by the model even after 17.9\% of the votes had been counted in Gauteng and 35\% counted in Limpopo? One of the reasons found was that the IEC delayed the release of the Gauteng results while the EFF called "foul play" and also contested many of the results in Gauteng $[9,29,33]$. These contentious VDs were held back to allow for the recounting and validation of the results and therefore were released late but these VDs also happened to be those with the strongest support for the EFF. This delay in a large chunk of VDs with a specific voting profile directly impacted the second major assumption used in the model since it introduced elements of excessive bias in the VD counting order. This lead to an "over" prediction of the ANC support at a very late stage of the count and an "under" prediction of the EFF support.

Another important aspect to consider relates to the clusters which form the basis of the first assumption. Could the poor performance of the ANC and EFF predictions also be a result of poorly constructed clusters due to the 2009 national results being a bad predictor of homogeneity in 2014 voter behaviour? To answer this question it was necessary to create a set of 20 "perfect" clusters, by using the known results at the end of the 2014 elections, and then simulating the election night predictions using these clusters and using the timestamp at which each voting district was declared.

The previous prediction results and the results from this simulation were graphed for comparison purposes. Figure 3 indicates the party deviances obtained on election night 2014, where the clusters used were constructed from 2009 election results (referred to as previous clusters) while Figure 4 displays the party deviances obtained from the simulation 


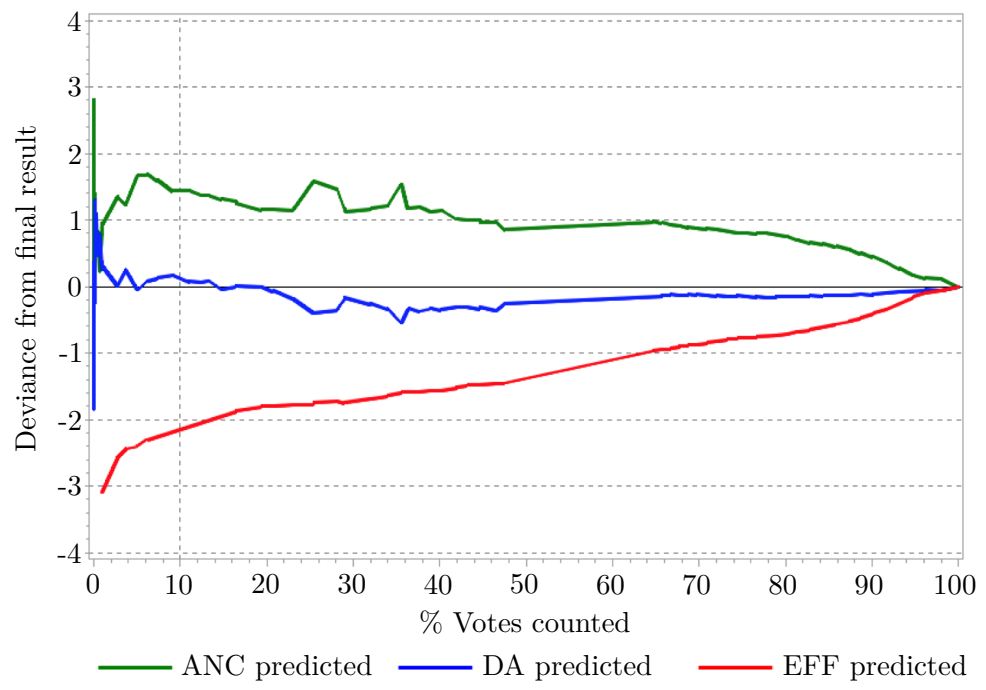

Figure 3: Deviance from the final result for the 3 top parties using the previous clusters.

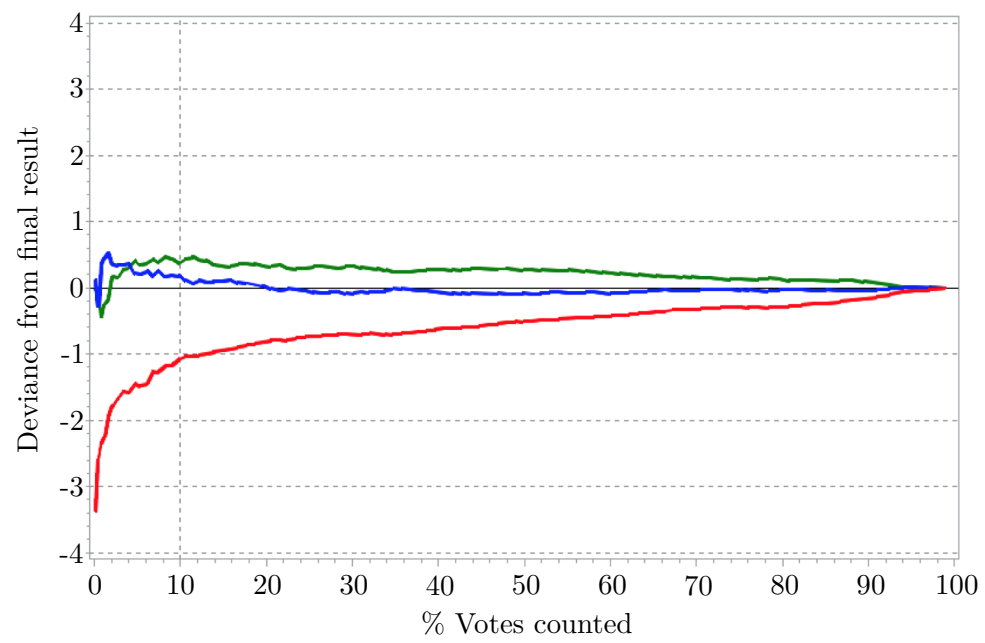

ANC predicted — DA predicted EFF predicted

Figure 4: Deviance from the final result for the 3 top parties using new clusters constructed from known 2014 results. 
when using new clusters based on the final 2014 results. One can see when comparing Figure 3 to Figure 4 that although there is little difference in performance between the sets of clusters for the DA predictions, which had already performed well on the night, there is a big improvement in the ANC predictions and also in the EFF predictions.

\begin{tabular}{|c|c|c|c|c|}
\hline \multirow{3}{*}{ Election year } & \multicolumn{4}{|c|}{$\begin{array}{l}\text { Percentage votes counted when error } \\
\text { measure drops and stays below } 1 \%\end{array}$} \\
\hline & \multicolumn{2}{|c|}{ MAE } & \multicolumn{2}{|c|}{ ANC deviance } \\
\hline & Predicted & Actual & Predicted & Actual \\
\hline 2014 (clustering on known results) & 1 & 42 & 0.2 & 36 \\
\hline
\end{tabular}

Table 8: Table of percentage votes counted at which MAE (for top 3 parties) and ANC deviance dropped and stayed below 1\%, for predicted and actual values in 2014 when clustering on known results.

Table 8 shows that if "perfect" clusters constructed from known results were used, it would result in the ANC prediction dropping and staying below a $1 \%$ deviance from $0.2 \%$ of votes counted while the MAE for the top 3 parties would have dropped below $1 \%$ after $1 \%$ of the votes had been counted.

Acknowledging the fact that one would not have access to "perfect" clusters, the overall results still indicate that the level of bias in the order in which the voting district results were declared was not the only issue and that the quality of the clusters was also a problem. It appears that the individual clusters created from 2009 national election results were not sufficiently homogeneous to cope with the change in voting behaviour experienced by the voting districts within each cluster. If the "perfect" clusters based on the known results were available, the national predictions for the DA and ANC would have both been within $0.5 \%$ of the final percentage vote all the way through the vote count (see Figure 4 ). The EFF prediction, however, only achieved this same accuracy after about $52 \%$ of the VDs had been declared and would have been within $1 \%$ of the final result after about $13 \%$ of the votes had been counted.

Considering that clusters are constructed on known results, there could be several reasons for the slower performance in the EFF predictions but as explained in $\S 3$, it is partially due to the distance measure used in the cluster construction. Since the clusters are built using the non-standardised distances, the parties with lower percentages do have less influence in the cluster formation than the larger parties and therefore predictions with clusters formed in this way are more accurate for the larger parties. As a result, predictions for the ANC, who obtained $62.15 \%$ of the national votes, will tend to be more accurate at an earlier stage than predictions for the EFF, who obtained $6.35 \%$ of the national votes.

In order to validate the previous statement regarding party size during the clustering process, the 2014 national results were re-clustered into 20 clusters, using a weighting added to the EFF votes in order to align their total votes to a similar magnitude as that of the ANC votes. This new set of clusters was applied to the simulation and the results obtained showed a large improvement in the EFF prediction results, dropping below $1 \%$ deviance from the start of the simulation, as can be seen in Figure 5. Figure 6 also shows the overall prediction improvement (reduction in MAE) for the top 3 parties for the EFF weighted new clusters compared to the standard new clusters and the previous clusters. 


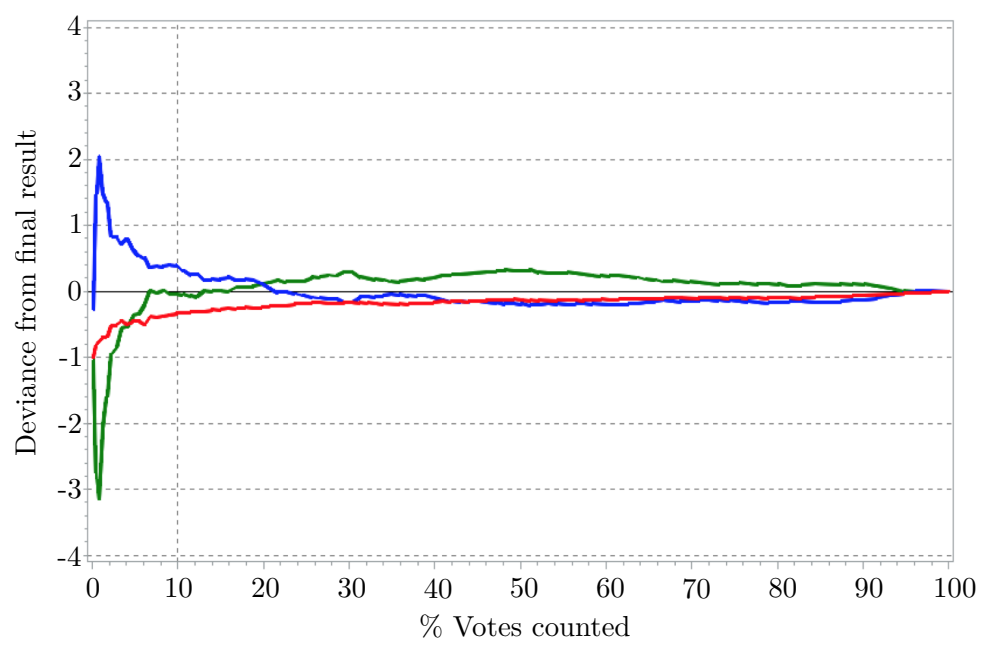

ANC predicted

DA predicted

EFF predicted

Figure 5: Deviance from the final result in 2014 using new clusters constructed with known 2014 results, with increased weights for EFF in clustering process.

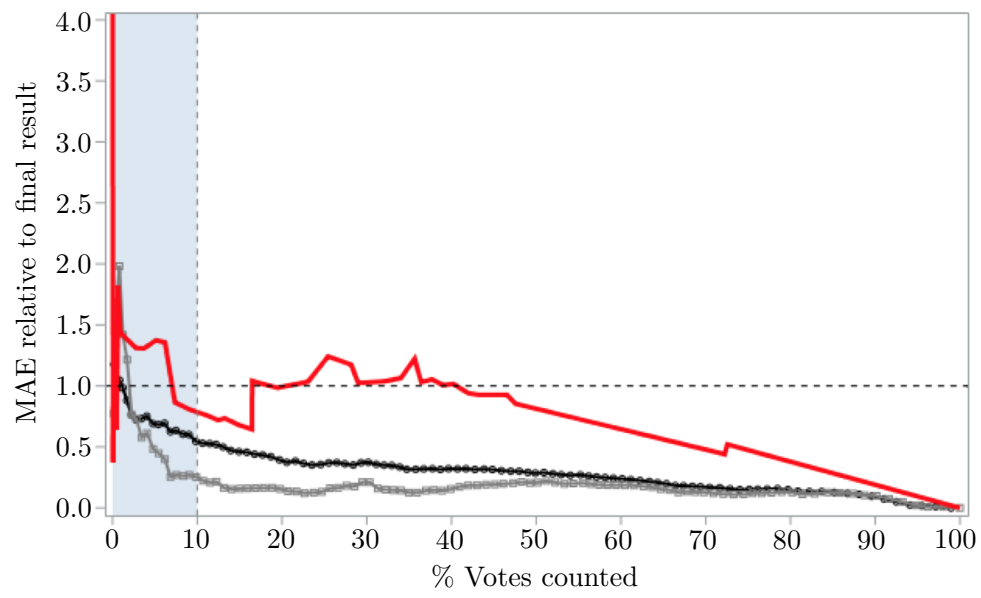

$\longrightarrow$ New clusters (known results)

— New clusters (known results, EFF weighted)

Previous clusters

Figure 6: MAE relative to final result in 2014 for top 3 party predictions using new clusters constructed with known 2014 results, with increased weights for EFF in clustering process. 


\begin{tabular}{lrr}
\hline & ANC & EFF \\
\hline Final number of votes received & 11436921 & 1169259 \\
Number of votes based on prediction & 11630378 & 883319 \\
Absolute difference & 193457 & 285940 \\
\hline
\end{tabular}

Table 9: Difference in votes between final and predicted results for the ANC and EFF.

The individual clusters created from the 2009 national elections were not sufficiently homogeneous to be able to cope with the introduction of the EFF party and the subsequent change in voting behaviour within each cluster that occurred in the 2014 elections. In addition, although the model can, to an acceptable level of accuracy, withstand the usual amount of bias in the order in which voting districts are declared if "good" clusters are used, the model cannot stand up very well to extreme bias and hence the holding back of contentious Gauteng results with large EFF support also impacted on the model behaviour.

\subsection{Importance of prediction variance}

Given the media exposure of the election predictions and the fact that the model performed very well in the past it was a concern and disappointment not only to the modelling team but also to the SABC that the predictions were not closer to the final results given that almost $50 \%$ of the VDs were declared. A further aspect is the importance that the political parties attach to the predicted outcome. Although all parties do their own predictions, an important additional source of comparison is the predictions from an "independent" source. Both these issues are important since it affects the credibility of the model as well as the accuracy of predictions. The predictions as discussed here affected the ANC and the EFF directly and the extent of this is shown here.

In South Africa more than 36 million people were eligible to vote although only 25388082 registered for the 2014 national election. Of these 18654771 voted with 252274 spoilt votes leaving 18402497 valid votes [19]. The voters are represented by 400 members in parliament. This implies that 46006 votes are equivalent to one seat, or one representative, in parliament. Table 9 gives the predicted votes with $49.3 \%$ of VDs declared and the actual final votes for the ANC and the EFF respectively as well as the absolute differences in votes between these two values.

Based on the predicted outcome, the ANC would have received an additional 4 seats while the EFF would have received 6 seats less. For the EFF this difference was large since the 6 seats represented just less than $25 \%$ of the ultimate 25 seats that the party won. The 4 additional seats the ANC would have gained were less important since the party finally won 249 seats during this election.

\section{Impact of assumptions and how they can be addressed}

The assumption that, if voting preferences were to change then all voting districts linked to a particular cluster (who had therefore voted in a similar pattern before) would change 
their voting behaviour in a similar way, proved not to hold true in the latest national elections, with only pockets of voting districts within clusters shifting their voting profiles. In addition, the assumption that large voter percentages declared equates to an almost completely representative voter profile across the clusters and therefore nationally, proved also to be problematic with late declarations of contentious VDs in Gauteng changing the national party tallies quite substantially towards the end. These VDs not only contained large registered populations but also exhibited voting profiles that were contrary to previous VDs released in their associated clusters. The failure of these assumptions in the 2014 election therefore became obstacles to producing accurate predictions, since the model itself actually performed correctly. It is therefore a major challenge to either avoid or compensate for a situation like this in the model. To have no assumptions would be preferred, but modellers know this is almost impossible. What happened in the 2014 election is possibly an exceptional occurrence and might not happen again. However, like Duckworth \& Lewis [8] indicated, well known for the Duckworth Lewis method used in interrupted cricket matches, no modeller wants to admit that the results produced by their model are questionable.

The objective of this paper was not to focus on possible changes to the model, but rather to scrutinize the predictions produced during the 2014 elections and to gain an understanding of what caused the prediction inaccuracies. The findings from the analysis presented here were, however, used to make improvements to the clusters used in the 2016 local elections. As a result these clusters were more robust with regard to assumption one, and this led to better prediction accuracy during the 2016 elections. However, it is very difficult to design robustness against a violation of assumption two and therefore, if it is suspected that assumption two will be unrealistic in future, an entirely new modelling approach may need to be developed for these election predictions.

\section{Conclusion}

This paper outlines a post-election analysis of the predictions produced by the election forecasting model for the 2014 general election in South Africa. The analysis was prompted by the fact that, with almost $50 \%$ of the voting district results available (equivalent to just over $40 \%$ of the estimated votes), the models prediction for two political parties, one of them being the large ANC party, were out by more than $1 \%$. This was contrary to previous elections where the predictions for the ANC, which has consistently been the largest party by far, were almost "spot on" with about $10 \%$ of the results released. A literature review illustrates some recent international examples where election predictions were totally wrong but reference is also made to elections where forecasts were fairly accurate. While the South African model produced accurate forecasts in previous elections at an early stage of the vote count, the predicted final results for the 2014 elections with almost $50 \%$ of VDs declared were not as expected. Through an in depth analysis it was possible to illustrate and show that the cause of this discrepancy could be attributed to two of the assumptions made in formulating the model. The aim of the paper was not only to determine what the reasons were for the "inaccurate" predictions but more importantly to make modellers aware of the pitfalls of model assumptions. In formulating models, 
assumptions have to be made, but their effects need to be investigated - it is therefore important to not only develop a model but also to monitor violation of assumptions during the course of implementing the model.

As modellers one always stresses the fact that the modelling results need to be interpreted with the assumptions in mind. Given the time pressure of election forecasts and the fact that almost $50 \%$ of the VDs were counted, it was extremely difficult to link the "under counting" in the largest province to the effect it would have on predicting the final outcome of the election. Even though it was clear upfront that the EFF had its strongest support in the Gauteng province and that most of this support came from ex-ANC supporters, with roughly $50 \%$ of the voting district results available one would have thought that the votes counted would have provided sufficient representation of voting behaviour to the clusters at a national level. However, the underlying clusters, based on 2009 voting patterns, proved to be inadequate in terms of grouping similar 2014 voting behaviour together and were unable to handle this swing in votes which occurred in certain pockets of Gauteng and also in areas of the North West province. In the end, slight inadequacies within the clusters, together with the IECs action of delaying the release of voting district results in Gauteng, had a direct negative impact on the accuracy of the predictions produced by the forecasting model. Post-analysis of the results clearly showed the impact of the violation of the model assumptions, and this prompted improvements to the model and a greater understanding of its limitations.

\section{Acknowledgement}

The authors would like to acknowledge other members of the core CSIR modelling team who have worked on the model over several election years, namely: Dr Jan Greben, Dr Chris Elphinstone, Dr Peter Schmitz, Rosalie de Villiers and Dr Zaid Kimmie; as well as the recent software support provided by Brenwen Ntlangu. The SABC is thanked for its support in this endeavour and also for giving the CSIR the opportunity to be involved in this exciting event.

\section{References}

[1] Alvarez-Rivera, M, 2004, Election Resources on the Internet: The Republic of South Africa Electoral System, Retrieved May 18, 2015, from Election Resources, Available from http:// electionresources.org/za/system/.

[2] Balinski ML \& Young HP, 2001, Fair representation: meeting the ideal of one man, one vote, Brookings Institution Press, Washington (D.C).

[3] BBC, 2015, Conservatives win 12-seat majority, Election 2015, Results, Retrieved May 18, 2015, from BBC, Available from http://www.bbc.com/news/election/2015/results.

[4] BBC, 2015, Election 2015: Poll Tracker, BBC Poll of Polls 6 May 2015, Retrieved May 18, 2015, from BBC, Available from http://www.bbc.com/news/politics/poll-tracker.

[5] Bezdek J, Trivedi M, Ehrlich R \& Full W, 1981, Fuzzy clustering: A new approach for geostatistical analysis, International Journal of Systems, Measurement and Decision, 1(2), pp. 13-24. 
[6] BezDeK JC, 1980, A convergence theorem for the fuzzy isodata clustering algorithms, IEEE Transactions on Pattern Analysis and Machine Intelligence, 1(1), pp. 1-8.

[7] Brown LB \& Chappell HW, 1999, Forecasting presidential elections using history and polls, International Journal of Forecasting, 15(2), pp. 127-135.

[8] Duckworth F \& Lewis T, 2011, Duckworth Lewis: The method and the men behind it, SportsBooks Limited, Cheltenham.

[9] Evans, S, 2015, EFF marches on IEC centre to demand Gauteng results, Retrieved May 18, 2015, from Mail \& Guardian, Available from http://mg.co.za/article/ 2014-05-09-eff-marches-on-iec-centre-to-demand-gauteng-results.

[10] Fara R, Leech D \& Salles M, 2014, Voting Power and Procedures, Springer-Verlag, Berlin.

[11] Fisher, S, 2015, Salutary lessons from the Israeli election polls 2015, Retrieved May 18, 2015, from Elections Etc, Available from http://electionsetc.com/2015/03/18/ salutary-lessons-from-the-israeli-election-polls-2015/.

[12] Greben JM, Elphinstone C \& Holloway J, 2006, A model for election night forecasting applied to the 2004 south african elections, ORiON, 22(1), pp. 89-103.

[13] Greben JM, Elphinstone C, Holloway J, De Villiers R, Ittmann H \& Schmitz P, 2005, Prediction of the 2004 national elections in south africa, South African journal of science, 101(3), pp. 157-161.

[14] Greene JP, 1993, Forewarned before forecast: Presidential election forecasting models and the 1992 election, Political Science \& Politics, 26(1), pp. 17-21.

[15] IEC, 2004, Election Report: 2004 National and Provincial Elections, Retrieved June 10, 2015, from Electoral Commission of South Africa, Available from http://www.elections.org.za/content/ Dynamic. aspx $? i d=1345 \& n a m e=E l e c t i o n s \& L e f$ tMenuId $=100 \& B r e a d C r u m b I d=220$.

[16] IEC, 2006, Detailed results data: 2006 Municipal Elections, Retrieved June 10, 2015, from Electoral Commission of South Africa, Available from http://www.elections.org.za/content/Dynamic . aspx?id=1625\&name=Elections\&Lef tMenuId=100\&BreadCrumbId $=220$.

[17] IEC, 2009, Election Report: 2009 National and Provincial Elections, Retrieved June 10, 2015, from Electoral Commission of South Africa, Available from http://www.elections.org.za/content/ Dynamic . aspx?id=1344.

[18] IEC, 2011, Municipal election results, Retrieved June 10, 2015, from Electoral Commission of South Africa, Available from http://www.elections.org.za/content/Error404/?aspxerrorpath= /content/Elections/Municipal-elections-\%20results/.

[19] IEC, 2014, National and Provincial Elections Results, Retrieved June 10, 2015, from Electoral Commission of South Africa, Available from http://www.elections.org.za/resultsnpe2014/.

[20] Ipsos, 2013, Ipsos survey: Political party support six months ahead of the election, Retrieved May 18, 2015, from Ipsos, Available from http://www.ipsos.co.za/SitePages/Support\%20for\% 20political\%20parties.aspx.

[21] IPsos, 2014, Political party support pre-election, Retrieved May 18, 2015, from Ipsos, Available from http://www.ipsos.co.za/SitePages/Political\%20party\%20support\%20pre-election.aspx.

[22] Ittmann H, 2011, Local government elections - Some personal perspectives, Proceedings of the $40^{\text {th }}$ ORSSA Annual Conference, Retrieved June 19, 2015, from ORSSA, Available from http://www. orssa.org.za/wiki/uploads/Conf/20110RSSAConferenceProceedings . pdf.

[23] Karandikar RL, Payne C \& Yadav Y, 2002, Predicting the 1998 Indian parliamentary election, Electoral Studies, 21(1), pp. 69-89. 
[24] Knight FH, 2012, Risk, uncertainty and profit, Riverside Press, New York (NY).

[25] Lauderdale B, 2015, How our U.K. election forecasting model works, Retrieved May 18, 2015, from Five Thirty Eight, Available from http://fivethirtyeight.com/features/ how-our-uk-election-forecasting-model-works/.

[26] Lewis-Beck MS, 2005, Election forecasting: Principles and practice, The British Journal of Politics and International Relations, 7(2), pp. 145-299.

[27] Lichtman AJ \& DeCell K, 1990, The thirteen keys to the presidency, Madison Books, Lanham.

[28] Morton RH, 1988, Election night forecasting in New Zealand, Electoral Studies, 7(3), pp. 269-277.

[29] NDLozI, MQ, 2015, EFF Demands the immediate release of Gauteng results, Retrieved May 30, 2015, from EFFighters, Available from http://effighters.org.za/ eff-demands-the-immediate-release-of-gauteng-results/.

[30] NIST/SEMATACH, 2013, NIST/SEMATECH e-Handbook of Statistical Methods (with updates), Retrieved May 5, 2015, from Information Technology Laboratory, Available from http://www.itl. nist.gov/div898/handbook/.

[31] Rothschild D, 2009, Forecasting elections comparing prediction markets, polls, and their biases, Public Opinion Quarterly, 73(5), pp. 895-916.

[32] Samuelson D, 2011, Elections 2012: The 13 keys to the White House, OR/MS, 38(3), pp. 26-28.

[33] SAPA, 2014, EFF claims foul play in Gauteng results, Retrieved May 30, 2015, from Citizen, Available from http://citizen.co.za/173197/eff-claims-foul-play-gauteng-results/.

[34] SiLver N, 2012, The signal and the noise: The art and science of prediction, Penguin Books, London.

[35] Tangian A, 2014, Mathematical Theory of Democracy, Springer-Verlag, Berlin.

[36] Thedeen T, 1990, Election prognosis and estimates of voter streams in Sweden, New Zealand Statistician, 25(1), pp. 54-58. 